\title{
A case report of greater saphenous vein thrombosis in a patient with coronavirus (COVID-19) infection
}

\author{
Negin Hesam-Shariati ${ }^{1}$, Poya Fatehi ${ }^{2}$, Fardin Fathi ${ }^{3}$, Morteza Abouzaripour ${ }^{4}$ and \\ Mohammad Bakhtiar Hesam Shariati ${ }^{4^{*}}$ (i)
}

\begin{abstract}
In December 2019, the World Health Organization (WHO) announced a series of pneumonia cases caused by an unknown origin, discovered in Wuhan, China. A dangerous virus called severe acute respiratory syndrome coronavirus 2 (SARS-CoV-2) caused a disease named acute respiratory syndrome, which was later popularly called coronavirus infection (COVID-19). Patients with acute COVID-19 are at high risk of thrombosis in various blood vessels due to hypercoagulability, blood stasis, and endothelial damage. In this study, we present a case report of a patient with COVID-19, who was hospitalized in one of the hospitals in Sanandaj, Iran. There were symptoms of fever, chills, muscle aches, cough, and tachycardia. Laboratory tests showed high levels of CRP, ESR, Ferritin CLIA, LDH and D-Dimer in this patient. Doppler ultrasound of the patient also revealed an abnormal finding, thrombosis in the right greater saphenous vein. This suggests that COVID-19 may lead to other negative effects through damage to blood vessels.
\end{abstract}

Keywords: Superficial vein thrombosis, Coronavirus, COVID-19, Ultrasonography, Case report

\section{Introduction}

Coronavirus has been widespread around the world since early 2020. The disease is highly contagious and, in severe cases, can lead to acute respiratory syndrome or organ failure [1, 2]. In January 2020, the World Health Organization (WHO) announced the outbreak of the disease as a "public health emergency of international concern" [3]. To date, the virus has led to an unprecedented global health crisis that has resulted in over 2 million death worldwide [4].

Several studies have shown that superficial vein thrombosis (SVT) is a common venous disease that appears to be medically benign but can cause serious complications and may be associated with complications such as deep

\footnotetext{
* Correspondence: b.hesamshariati@gmail.com; m.hesamshariati@muk.ac.ir ${ }^{4}$ Department of Anatomical Sciences, Faculty of Medicine, Kurdistan University of Medical Sciences, Sanandaj, Iran

Full list of author information is available at the end of the article
}

vein thrombosis (DVT) and pulmonary embolism (PE) $[5,6]$. The prevalence of SVT is estimated to be about 3 to $11 \%$, while the incidence of thrombosis in the greater saphenous vein (GSV) is about 60 to $80 \%$ of the time [7, 8]. The proximity of the greater saphenous vein to the saphenofemoral junction (SFJ) increases the possibility of displacement of blood clots and their entry into the deep venous system and as a result makes SVT a serious concern [9].

There is a risk for venous and arterial thrombosis in patients with SARS-Cov2 due to excessive coagulation status, blood stasis, and damage to vascular endothelial cells in this condition [10]. As the clinical signs of venous and arterial thrombosis are ambiguous, it is very important to use imaging techniques such as Doppler ultrasound and computed tomography (CT) angiography to prevent catastrophic complications such as pulmonary 
embolism and mortality [11]. In this case report, the course of a patient with coronavirus is described.

\section{Case presentation}

A 40-year-old man with one-week symptoms of cough, fever, fatigue, muscle aches, diarrhea, palpitations, and shortness of breath but no chest pain was admitted to Tohid Hospital, Sanandaj, Iran. Before admission, the patient was diagnosed with COVID-19 by an infectious disease specialist based on the initial symptoms. Both CT scans (Fig. 1) and the real-time reverse transcriptasepolymerase chain reaction (RT-PCR) confirmed the infection. The patient had no history of underlying diseases such as diabetes, heart disease, hypertension, or cancer. At the hospital's emergency department, the physical examinations showed that the patient had an irregular heart rate of 145 beats $/ \mathrm{min}$, blood pressure of $82 / 75 \mathrm{mmHg}$, temperature of $38.4^{\circ} \mathrm{C}$, respiratory rate of 26 breaths/min, and oxygen saturation of $89 \%$. Paraclinical and laboratory results showed that routine blood tests, renal function, and electrolytes were completely normal. The influenza A and B antigen tests were also negative. However, the other laboratory findings were all abnormal, which are briefly listed in Table 1. In CT scans of the lungs (Fig. 1), bronchovascular marking is evident. Additionally, multiple foci of parenchymal turbidity and ground-glass opacity were observed with greater density at the margins and at the base of the lungs. Therefore, the patient was started on medical treatment with Naproxen, Hydroxychloroquine, Famotidine, Zinc, Neurobion, and anticoagulants by injecting heparin and taking acetylsalicylic acid tablets.

Three days after hospitalization, Doppler ultrasound was performed on the lower limb due to numbness and tingling (paresthesia) in the right leg, in addition to swelling, redness, pain, and sensitivity to touch. Examination of the main veins of both lower limbs showed no evidence of occlusion in the external iliac, common femoral, popliteal, anterior and posterior tibialis, and peroneal. However, more detailed examination revealed that thrombosis was evident at the beginning of the greater saphenous vein of the right leg from distal to proximal (Fig. 2). The patient was discharged after 12 days of hospitalization with complete recovery from COVID-19. The anticoagulation treatment for the GSV thrombosis was continued for the patient, and no negative side effect caused by SVT was reported after the treatment.

\section{Discussion}

In this case report, we presented a patient with COVID19 who was hospitalized in Tohid Hospital, Sanandaj, Iran and later was diagnosed with a thrombosis in his right GSV. This patient had common COVID-19 symptoms such as fever, dry cough, shortness of breath, and muscle pain [12] but no risk factor for SVT. Paraclinical tests and CT scans of the chest confirmed the COVID-19 diagnosis, and although there was no obvious evidence of SVT, detailed examination by Doppler ultrasound revealed a thrombosis in the patient's GSV.

Studies have shown that the most important and stable hemostatic disorders associated with COVID-19 include mild thrombocytopenia [13] and an increase in D-dimer amount [14]. There is evidence showing thrombotic abnormalities, in addition to abnormalities in the function of various organs in patients with COVID-19 [15], which lead to higher mortality. However, as far as we can ascertain there are few reports of SVT and its side effects in patients with COVID-19.

Pathophysiologically, patients with COVID-19 may have a higher risk for developing venous thrombosis, usually due to diarrhea, hypotension, recurrent longterm infections, and dehydration [16]. Therefore, in patients with coronavirus, assessing the risk of DVT and SVT are essential to reduce complications and mortality risk. Studies have shown that patients prone to DVT usually have one of the following criteria: age over 75 , respiratory and heart failure, history of previous thrombosis, acute onset of chronic pulmonary obstruction, acute cerebral infarction, malignant tumor, limb varicose veins, obesity, chronic kidney disease, inflammatory bowel disease, and more than 3 days of bed rest [17].

In one study on a patient with COVID-19, CT images of angiography showed signs of acute cerebral infarction and DVT in both lower limbs [18]. In our case report, the patient was suspected of having thromboembolism due to having similar lesions on his leg, however after a CT scan of his chest, his diagnosis with COVID-19 was confirmed, while there was no evidence of pulmonary thromboembolism. The physicians at the hospital also suspected SVT and DVT due to numbness, swelling, and pain in the right leg, which were examined by Doppler ultrasound of all blood vessels, including the common iliac, small saphenous, and greater saphenous. Since many studies have reported respiratory distress along with other clinical evidence of venous thrombosis, pulmonary embolism should be suspected $[19,20]$.

A recent study on the intensive care unit (ICU) patients with COVID-19 found that the rate of thrombotic disorders in these patients is 31\% [21]. Further, medical images have shown that $27 \%$ of such thrombotic disorders are due to venous thromboembolism, 3.7\% to arterial thrombosis, and $81 \%$ to pulmonary embolism, which is the most common complication of thrombosis in ICU patients [21]. The possible reasons for venous thrombosis may include the fact that COVID-19 attacks the human body via the 2-angiotensin converting enzyme, which is found in various blood vessels and organs of 

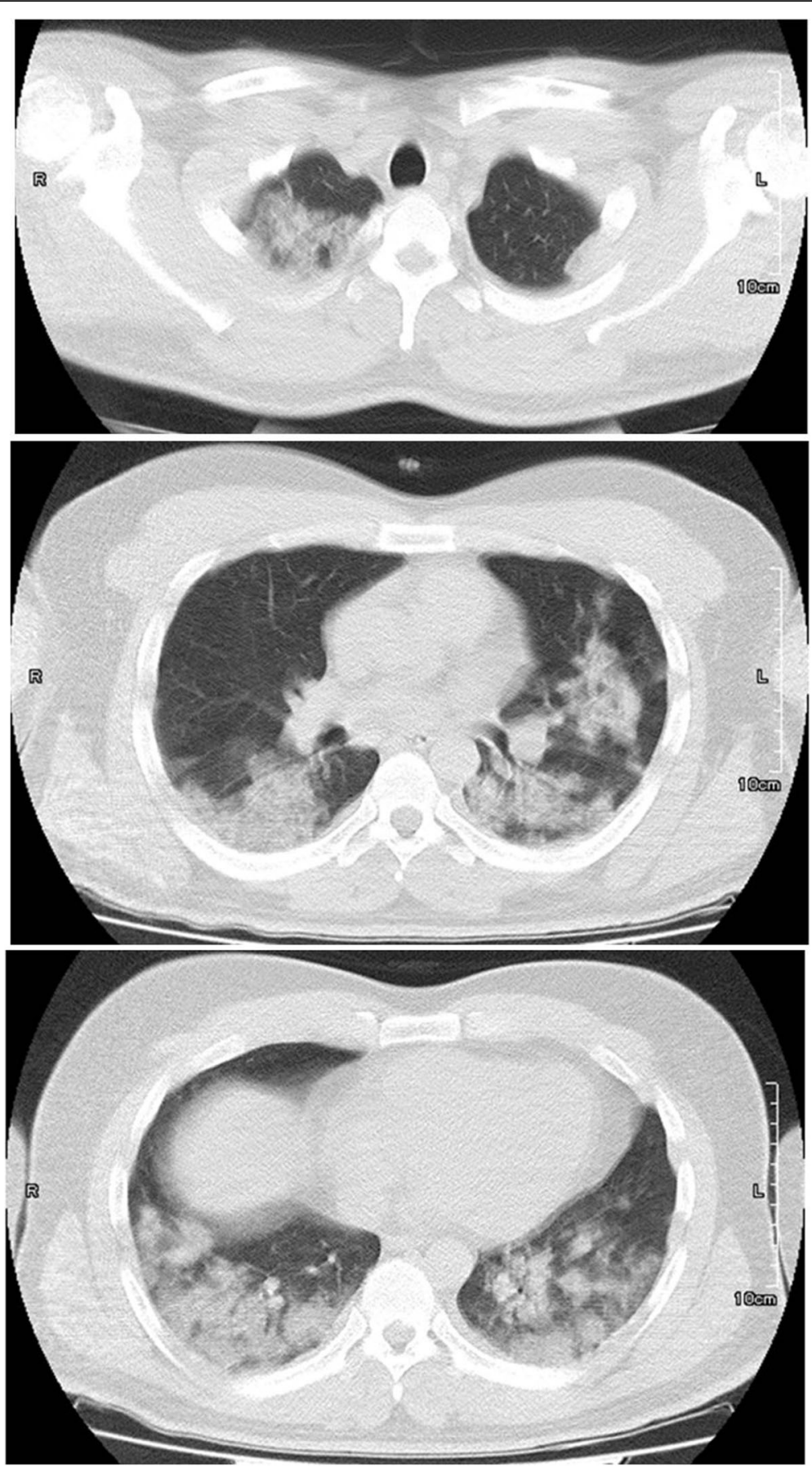

Fig. 1 Axial without contrast-enhanced chest computed tomography (CT) image showing a coronavirus disease (COVID-19) infection

the body [22]. Ultimately, coronaviruses cause cytokine waterfalls, including IL2, IL7, IL10, GCSF, IP10, MCP1, MIP1A, and TNF $\alpha$ in the body, which can increase the risk of complications such as blood clots. This cytokine storm can be associated with the severity of the disease and its negative consequences [23, 24]. Blood clots formed in DVT may also have a variety of causes, including vascular damage, surgery, special medications, and limited mobility [25], but the exact cause of COVID-19-induced DVT is still unknown [26].

\section{Conclusion}

COVID-19 is an emerging source of venous thrombosis due to factors such as excessive coagulation, blood stasis, 
Table 1 The results of laboratory findings

\begin{tabular}{|c|c|c|c|c|c|}
\hline & Test Name & Unit & Reference range & Results & Flag \\
\hline 1 & BUN & $\mathrm{mg} / \mathrm{dl}$ & $6-20$ & 32 & $\mathrm{Hi}$ \\
\hline 2 & CPK & $\mathrm{IU} / \mathrm{L}$ & male: 0-171 & 55 & \\
\hline 3 & $\mathrm{LDH}$ & $U / L$ & $235-470$ & 510 & $\mathrm{Hi}$ \\
\hline 4 & $\mathrm{Na}$ (ser) & $\mathrm{mEq} / \mathrm{L}$ & $138-145$ & 134 & LOW \\
\hline 5 & $\mathrm{~K}(\mathrm{ser})$ & $\mathrm{mEq} / \mathrm{L}$ & $3.6-5.9$ & 3.8 & \\
\hline 6 & $\mathrm{Cr}$ & $\mathrm{mg} / \mathrm{dl}$ & male:0.8-1.3 mg/dl & 0.7 & LOW \\
\hline 7 & CRP & $\mathrm{mg} / \mathrm{l}$ & $0-6$ & 30 & $\mathrm{Hi}$ \\
\hline 8 & ESR & $\mathrm{mm}$ & $5-12$ & 18 & $\mathrm{Hi}$ \\
\hline 9 & Ferritin CLIA & $\mathrm{ng} / \mathrm{mL}$ & $50-434$ & 511 & $\mathrm{Hi}$ \\
\hline 10 & D-Dimer(CLIA-Siemens) & $\mathrm{ng} / \mathrm{mL}$ & $<885$ & $>7500$ & $\mathrm{Hi}$ \\
\hline
\end{tabular}

and endothelial damage. The main mechanism of SVT and DVT formation due to COVID-19 is unknown and has not yet been examined. Although COVID-19 cases presented with SVT and DVT are rare, recognizing SVT and DVT as potential complications of COVID 19 infection will be of great value.
Imaging techniques such as CT, MRI, and ultrasound can confirm the diagnosis of SVT and DVT. Due to the possibility of COVID-19 infection in patients presenting with venous thrombosis or other thromboembolic diseases, it seems important to consider the presence of COVID-19 in their diagnosis.

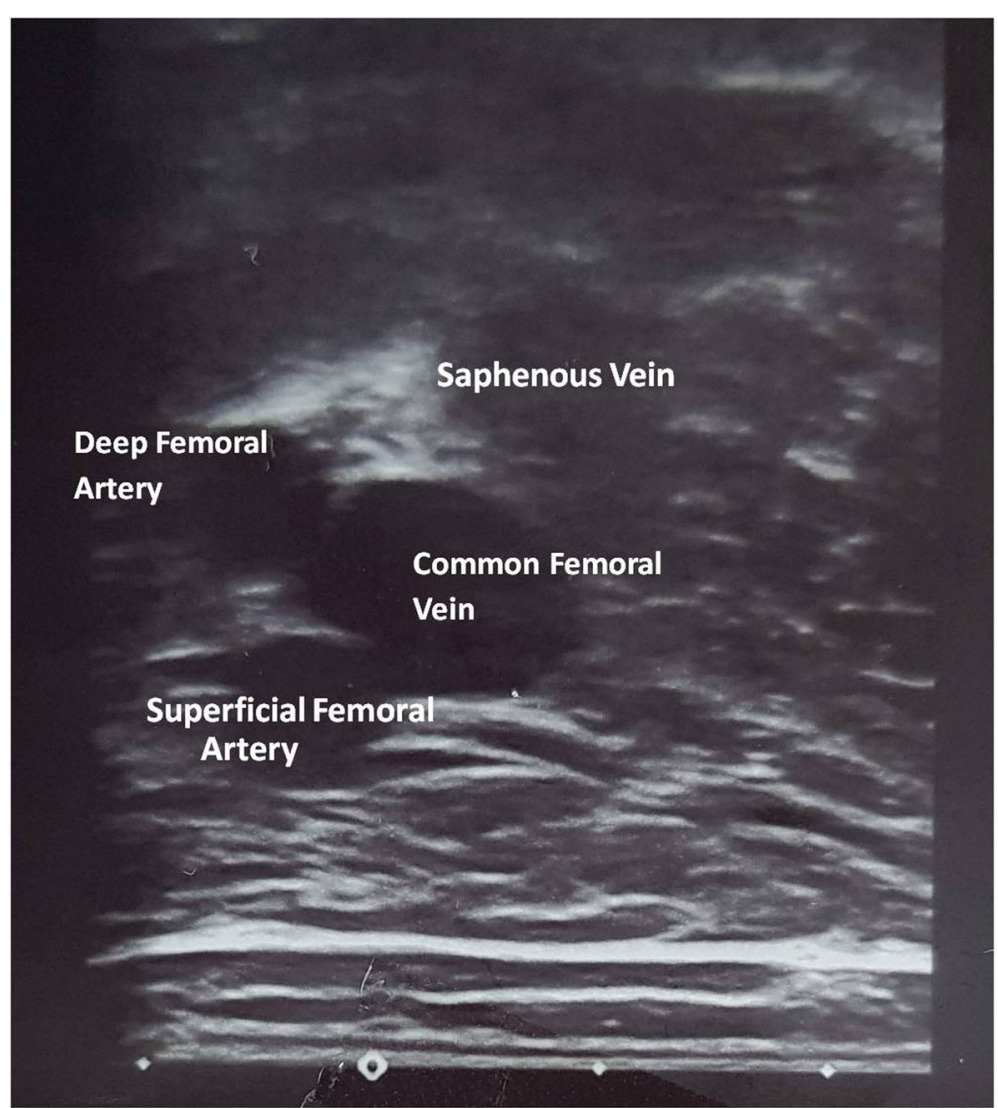

Fig. 2 Doppler ultrasound images of the lower right limb showing a superficial vein thrombosis (SVT). Anterior accessory saphenous vein (AASV), great saphenous vein (GSV), common femoral vein (CFV), and common femoral artery (CFA) in the Doppler ultrasound images of the lower right $\operatorname{limb}$ 


\section{Acknowledgements}

The authors thank all the teaching and medical staff of Kurdistan University of Medical Sciences for their effort in eradicating the virus around the clock.

\section{Authors' contributions}

MBHS supervised the study and wrote the manuscript; PF collected the clinical data; MA and FF analyzed the data and images; and NHS reviewed the manuscript. The author(s) read and approved the final manuscript.

\section{Funding}

No source of funding.

\section{Availability of data and materials}

I have presented the data of the patient in the manuscript as a Table. I have submitted the figures separately as figures.

\section{Declarations}

Ethical approval and consent to participate

This research has been confirmed by the Research Center of Kurdistan University of Medical Sciences and Ethics Committee with the file number IR.MUK.REC.1399.087.

\section{Consent for publication}

Written informed consent was obtained from a legally authorized representative(s) for anonymized patient information to be published in this article which was approved by the Research Center of Kurdistan University of Medical Sciences.

\section{Competing interests}

All authors declare that there is no conflict of interest that prejudices the impartiality of this scientific work.

\section{Author details}

'School of Medical Sciences, Faculty of Medicine, University of New South Wales, Sydney, Australia. ${ }^{2}$ Department of Radiology, Tohid Hospital, Kurdistan University of Medical Sciences, Sanandaj, Iran. ${ }^{3}$ Cellular and Molecular Research Center, Research Institute for Health Development, Kurdistan University of Medical Sciences, Sanandaj, Iran. ${ }^{4}$ Department of Anatomical Sciences, Faculty of Medicine, Kurdistan University of Medical Sciences, Sanandaj, Iran.

Received: 30 September 2020 Accepted: 21 February 2021

Published online: 03 March 2021

\section{References}

1. Holshue ML, et al. First case of 2019 novel coronavirus in the United States. N Engl J Med. 2020;382(10):929-36.

2. Wang D, et al. Clinical characteristics of 138 hospitalized patients with 2019 novel coronavirus-infected pneumonia in Wuhan, China. JAMA. 2020; 323(11):1061-9.

3. Li L, et al. Using Artificial Intelligence to Detect COVID-19 and Communityacquired Pneumonia Based on Pulmonary CT: Evaluation of the Diagnostic Accuracy. Radiology. 2020;296(2):E65-71.

4. Lodigiani $\mathrm{C}$, et al. Venous and arterial thromboembolic complications in COVID-19 patients admitted to an academic hospital in Milan, Italy. Thromb Res. 2020;191:9-14.

5. Sobreira ML, et al. Prevalence of deep vein thrombosis and pulmonary embolism in superficial thrombophlebitis of the lower limbs: prospective study of 60 cases. Int Angiol. 2009;28(5):400.

6. Subramaniam P, Van Doornum S. Superficial thrombophlebitis: underlying hypercoagulable states. Aust N Z J Surg. 1999;69(6):461-3.

7. Decousus H, Leizorovicz A. Superficial thrombophlebitis of the legs: still a lot to learn. J Thromb Haemost. 2005;3(6):1149-51.

8. Leon L, et al. Clinical significance of superficial vein thrombosis. Eur J Vasc Endovasc Surg. 2005;29(1):10-7.

9. Sover ER, Brammer HM, Rowedder AM. Thrombosis of the proximal greater saphenous vein: ultrasonographic diagnosis and clinical significance. J Ultrasound Med. 1997;16(2):113-6.
10. NHCotPsRo, C., New coronavirus pneumonia prevention and control program (seventh trial edition). http://www.nhc.gov.cn/xcs/zhengcwj/202 002/3b09b894ac9b4204a79db5b8912d4440.shtml, 2020.

11. Dunnihoo DR, et al. Postpartum ovarian vein thrombophlebitis: a review. Obstet Gynecol Surv. 1991;46(7):415-27.

12. Li, Y., et al., Lack of vertical transmission of severe acute respiratory syndrome coronavirus 2, China. 2020.

13. Lippi G, et al. Thrombocytopenia is associated with severe coronavirus disease 2019 (COVID-19) infections: A meta-analysis. Clin Chim Acta. 2020; 506:145-8.

14. Terpos $\mathrm{E}$, et al. Hematological findings and complications of COVID-19. Am J Hematol. 2020;95(7):834-47.

15. Vickers NJ. Animal communication: when i'm calling you, will you answer too? Curr Biol. 2017;27(14):R713-5.

16. Zhou B, et al. Venous thrombosis and arteriosclerosis obliterans of lower extremities in a very severe patient with 2019 novel coronavirus disease: a case report. J Thromb Thrombolysis. 2020;50(1):229-32.

17. Wells PS, Forgie MA, Rodger MA. Treatment of venous thromboembolism. JAMA. 2014;311(7):717-28.

18. Zhou B, et al. A case of coronavirus disease 2019 with concomitant acute cerebral infarction and deep vein thrombosis. Front Neurol. 2020;11:296.

19. Xie Y, et al. COVID-19 complicated by acute pulmonary embolism. Radiol Cardiothorac Imaging. 2020;2(2):e200067.

20. Danzi GB, et al. Acute pulmonary embolism and COVID-19 pneumonia: a random association? Eur Heart J. 2020;41(19):1858.

21. Klok FA, et al. Incidence of thrombotic complications in critically ill ICU patients with COVID-19. Thromb Res. 2020;191:145-7.

22. Zhang $\mathrm{H}$, et al. Angiotensin-converting enzyme 2 (ACE2) as a SARS-CoV-2 receptor: molecular mechanisms and potential therapeutic target. Intensive Care Med. 2020;46(4):586-90.

23. Zheng Y-Y, et al. COVID-19 and the cardiovascular system. Nat Rev Cardiol. 2020;17(5):259-60.

24. Huang C, et al. Clinical features of patients infected with 2019 novel coronavirus in Wuhan, China. Lancet. 2020;395(10223):497-506.

25. Tarannum N, Azam MS, Premchand RK. May-Thurner syndrome and recurrent DVT: a case report. Indian J Clin Cardiol. 2020;1 (1):13-6.

26. Davoodi L, et al. COVID-19 presented with deep vein thrombosis: an unusual presenting. J Investig Med High Impact Case Rep. 2020;8: 2324709620931239.

\section{Publisher's Note}

Springer Nature remains neutral with regard to jurisdictional claims in published maps and institutional affiliations.

Ready to submit your research? Choose BMC and benefit from:

- fast, convenient online submission

- thorough peer review by experienced researchers in your field

- rapid publication on acceptance

- support for research data, including large and complex data types

- gold Open Access which fosters wider collaboration and increased citations

- maximum visibility for your research: over $100 \mathrm{M}$ website views per year

At BMC, research is always in progress.

Learn more biomedcentral.com/submissions 